\title{
Propuesta para el desarrollo de un programa de formación en promoción de la lectura en las escuelas de bibliotecología
}

\author{
Didier Alvarez Zapata \\ Escuela Interamericana de Bibliotecología \\ de la Universidad de Antioquia
}

\section{RESUMEN}

Este documento esboza las líneas generales de una propuesta de desarrollo para el área de promoción de la lectura en las escuelas de bibliotecología del ámbito latinoamericano. Para ello considera el contexto mundial dentro del cual se mueven hoy las prácticas lectoras; el papel de la bibliotecología frentea esa situación; la descripción de la problemática del área, y un conjunto de objetivos y reflexiones que pueden seguirse para iniciar un programa en el área.

Palabras clave: Promoción de la Lectura, Formación de Usuarios, Escuelas de Bibliotecología, América Latina.

\section{PROPOSAL FOR THE DEVELOPMENT IN LIBRARY SCHOOLS \\ OF A TRAINING PROGRAM TO PROMOTE READING \\ Didier AlvareZ-Zapata}
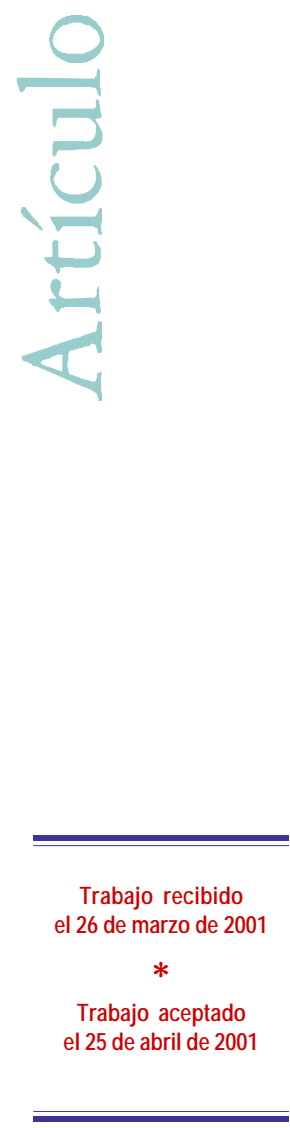

\section{ABST RACT}

This document sketches the general outlines of a proposal to develop an area for the promotion of reading in library schools in Latin America. As a result it is necessary to consider the global context in which reading habits are situated today; the role of the library scientist in the face of this situation; the description of the problems in this area, and the set of objectives and reflections that can be followed to initiate a program in the area.

Key words: Reading Promotion, User Formation, Library Schools, Latin America. 


\section{INTRODUCCIÓN}

$\mathbf{E}$ s tiempo de construir una idea más viva de la biblioteconomía ${ }^{1}$ y de la biblioteca, una idea que las acerque al hombre común, que las haga crecer al calor del vivir y el leer, del ser y el transformar. Frente a concepciones apocadas de la biblioteca (almacén, depósito, rincón u otra clase de laberinto o subterfugio del poder), y de la biblioteconomía (una técnica, no más... ) urge construir una institución y una disciplina directamente vinculadas al hombre en lo individual y en lo colectivo. Una institución y una disciplina - por ello mismo dignas y necesarias- en las que se asuma el trato con el otro, con el conocimiento y los materiales de lectura, como una "función viviente" (según la dimensión Orteguiana). ${ }^{2}$ Esto es, que sepan cómo participar en la producción social de conocimiento, que tengan un activo papel en el proceso de constitución de las sociedades. Por ello la pramoiónde la Leetura debe ser una práctica común al trabajo biblioteconómico; una actividad integrada a las tareas regulares y cotidianas de la biblioteca, una actitud institucional y un empeño disciplinario.

\section{EL CONTEXTO DE LAS PRÁCTICAS LECTORAS: UN MUNDO EN CRISIS}

A las puertas de un nuevo milenio asistimos a una tremenda conmoción del mundo. Un mundo en el que, al parecer, sólo hay un acuerdo: que estamos en crisis. En crisis de todo. En crisis por todo. En crisis frente a todo. Y es que la humanidad no había vivido algo similar hasta ahora. Nada había ocurrido parecido a este ensueño caleidoscopio que incluye a una muchedumbre de seis mil millones de personas viviendo en un planeta visiblemente agobiado, lleno de dolor y guerra; la experiencia de la aldea global invocada por MacLuhan. Esta crisis podría ser reconocida como un "...estado intelectual, social, económico, político, cultural donde la perturbación es tan grande que ya no se disciernen las salidas posibles." ${ }^{3}$ Fuerza que ha generado el cambio de las relaciones temporales y espaciales, de las nociones de mundo y hombre. Una fuerza que reconfigura, constantemente, un mundo que, tal cual la lava de un volcán en efervescencia, podrá en su rodar tomar los más insospechados cursos. Fuerza que trae el vértigo de ideas, la hegemonía del "TobVale" (Heller). Una fuerza que hace que el mundo se nos deslice por entre las manos, en tanto que expresión de ese trastocamiento temporal y espacial: aparición

1 Aquí se asume, epistemológicamente, a la Biblicteconomáa como una de las disciplinas que constituyen a la Biblictecoloǵa o Cienaia dela Infomacón (Biblioteconomía, o disciplina de las bibliotecas; Archivística, o disciplina de los archivos; D ocumentación, o disciplina de los procesos documentales y de los centros de documentación; museología, o disciplina de los museos).

2 Ortega y Gasset, José. "Misión del bibliotecario”. Madrid : Reista deOcidante 1962.

3 Tenzer, Nicolas. La sociedad despoditizada Barcelona. Paidós, 1962. 
de la virtualidad, rompimiento de las barreras del tiempo geográfico en virtud de un tiempo total, de un tiempo mundial que exige en cualquier lugar vivir en "tiempo real".

Un mundo que corre angustiosamente hacia lo impredecible empujado por la carga de una profunda crisis de civilización (Tenzer). Una profunda crisis frente a la cual todo intento de explicación general resulta parcial en cuanto que es increíblemente difícil explicar su globalidad sin hacerlo desde aspectos laterales. Fenómeno que muy rápidamente podría ser caracterizado como una crisis global generalizada del proyecto civilizatorio moderno que implica impactos globales, pero efectos de variada intensidad en las personas, las culturas, las sociedades y los Estado-naciones. Una crisis de lo colectivo para la acción frente a lo público (descrédito de la política, debilitamiento de la autopoiesis - capacidad de autogeneración del sistema social- y de la posibilidad real que tienen los individuos para conducir la vida particular). Tal crisis no se genera en externalidades sino, al contrario, en factores constitutivos de la estructura interna de las culturas y las sociedades: En el desteñimiento de sus imaginarios, el derribamiento de sus utopías, en la angustia histórica generada en un agudo traslape espacio temporal en el que, del entusiasmo de la modernidad, se ha pasado al desencanto de lo postmoderno: Fracaso del proyecto moderno, como lo plantean Vattimo y Lyotard, entre otros. Crisis, en fin, de un mundo donde ni lo nuevo acaba de aparecer, ni lo viejo acaba de desaparecer. Crisis que se autosustenta y amenaza con no dejar nada en pie.

\section{LAS PRÁCTICAS LECTORAS EN UN MUNDO EN CRISIS}

En particular, dentro de todo esto, el hecho es que se asiste a la aparición de un nuevo modelo de sociedad. Una sociedad que venía cuajando ya desde hace mucho. Una sociedad signada por urgencias, en la que se ponen en escena nuevas identidades y nuevas maneras de relacionarse, nuevas maneras de producir y consumir, nuevos productos culturales y, sobre todo, otras prácticas culturales compulsivamente dirigidas, ahora, a la construcción de nuevos sentidos, de nuevas significaciones para la vida, para el mundo, para el otro, para sí mismo.

En esta perspectiva, la lectura sufre hoy intensas transformaciones, como todo lo que constituye el mundo-idea del que venimos, el mundo moderno, el mundo de las utopías democráticas, científicas y económicas propuestas por el espíritu de la modernidad occidental, aparentemente triunfante con sus ideales ilustrados, añejos anhelos revolucionarios. La lectura está siendo fuertemente cuestionada. Pero, sobre ella, no obstante, se siguen cimentando grandes esperanzas de progreso para la humanidad. D esde las más diversas e incluso divergentes corrientes del pensamiento social, la lectura es considerada fundamental para alcanzar un mundo en el que sea posible vivir para la libertad, la igualdad y la fraternidad. En un sorprendente 
acuerdo reconocen esto tanto el pensamiento más funcionalista como el más crítico; todos bajo la sombra de los sueños de la modernidad a sus espaldas.

En este sentido, confluyen pensamientos políticos tan distantes como el socialismo y el liberalismo señalando la importancia social y política que tiene la lectura. Las dos grandes potencias de la guera fía, USA y URSS, por ejemplo, desplegaron ingentes esfuerzos por elevar y cualificar las capas lectoras en sus países, y desarrollaron poderosos sistemas bibliotecarios y educativos centrados en el desarrollo de las habilidades de literacy (habilidades relacionadas con el leer y el escribir comprensivamente). ${ }^{4}$ Aún más, en el contexto latinoamericano no puede olvidarse la presencia de importantes figuras que alentaron la lectura y la escritura como forma de construir la identidad individual y colectiva a partir de pensamientos a veces cercanos y a veces muy lejanos: José Martí y su amado proyecto editorial de la EdaddeOro Paulo Freire, desde el inmenso Brasil, y su pedagogía del oprimido: aprender a leer y a escribir para liberarse; Sanín Cano, en Colombia, y su proyecto de lectura pública y generalizada con la punta de lanza en la famosísima colección de libros BiblictecaA Aldeana; etcétera.

Todas estas posiciones, no obstante, estaban puestas ante un hecho irrefutable: la lectura. Ésta, aunque generalizada como actividad meramente descodificadora por las vías de los programas de cobertura educativa de una escuela que aún oficia una lectura mecánica y funcionalista, dista todavía muchísimo de ser una práctica cultural generalizada que esté realmente puesta en la ruta de la construcción de una cotidianidad trascendente. Ya Roland Barthes ${ }^{5}$ lo advertía casi treinta años atrás: "la actividad de leer se retrae en la misma medida en que la qparacón de leer se universaliza." Una sentencia dura pero cierta si se considera el lugar secundario que ocupa la lectura en nuestra sociedad.

\section{LA BIBLIOTECA:}

\section{UNA PRESENCIA EN LA CAUSA POR LA LECTURA PLENA}

En este contexto de agitación del mundo y, en específico, de cambio de las prácticas culturales y de socialización de los sujetos, la lectura ha ganado posición dentro del pensamiento bibliotecario latinoamericano y, más específicamente, en

4 Los bibliotecólogos de la escuela de Chicago (USA) ya veían desde principios del siglo XX, con gran claridad, el papel que la biblioteca debía jugar en los propósitos de transformación social. Las grandes oleadas de inmigrantes europeos a USA, encontraron, siempre, en la biblioteca pública, un espacio esencial de integración a la nueva cultura que los acogía. También los políticos y planificadores socialistas en la URSS tomaron en cuenta la importancia estratégica de la biblioteca. Lenín se tomó el trabajo de idear y describir el sistema bibliotecario soviético resaltando, con gran énfasis, el valor de la lectura en las así llamadas "bibliotecas de masas".

5 Citado por Petrucci, Armando. Leer por leer: un parvenir para la lectura Barcelona. Alianza, 1994. p. 123. 
las prácticas bibliotecarias públicas y escolares. De este interés por la promoción de la lectura, ni el bibliotecario, ni la biblioteca, ni la bibliotecología pueden ya alejarse. Se ha vuelto un campo obligado del desarrollo disciplinario y del ejercicio profesional.

En esta perspectiva, las escuelas de bibliotecología deben asumir con decisión el área en sus currículos como una línea de investigación. Pero en esto, por diversas causas, ha habido poco empeño y continuidad académicos y el área vive fuera de las universidades. En particular, son notables las dificultades que existen para echar una verdadera mirada académica sobre este campo, y formar una comunidad disciplinaria e interdisciplinaria. A esto hay que agregar la supervivencia de un imaginario y una actitud pragmatista y formulística en la sociedad frente a la promoción de la lectura, lo que hace aparecer a ésta como un asunto lleno de espectacularidad y sólo para niños y, en ocasiones, para jóvenes. Como consecuencia de esto, es decir de la ausencia de un biblictecariohumanista(con una clara vocación lectora) éste ha sido reemplazado por la figura exótica del promotor de lectura, tan escaso de tiempo, a veces, como de visiones realmente adscritas al reconocimiento de una tradición bibliotecaria sólida con base en la cual pueda fundar su trabajo.

\section{La promoción de la lectura: la acción social por excelencia de la biblioteca}

La promoción de la lectura debe entenderse como un trabajo de intervención sociocultural que busca (a partir de la revalorización, transformación y construcción de nuevos sentidos, idearios y prácticas lectoras), generar cambios en las personas, en sus contextos y en sus interacciones. Para ello intenta (desde una clara perspectiva comunicativa) fortalecer a los lectores como actores sociales, capaces de responder a los retos vitales, sociales, culturales, políticos y aun económicos. La promoción de la lectura parte de reconocer las problemáticas de la vida individual y colectiva, y le da a la lectura el valor histórico que le corresponde a la vez que enfatiza su íntima relación con la escritura.

Si se entiende a la promoción de la lectura de esta forma, se debe aceptar también que una biblioteca de cualquier tipo que quiera ejercerla, debe apropiarse de dos cosas:

Primero, desarrollar las funciones de recuperación, organización y difusión de la información en y para la producción de niqueza soial: inteligencia colectiva que ayude a enfrentarse con éxito al mundo como un proyecto. Riqueza que inunde la vida cotidiana: lo artístico, lo educativo, lo científico y tecnológico, lo laboral y lo político (referido a los espacios, oportunidades y mecanismos de participación y decisión). 
Propuesta para el desarmollo de un programa de formación en promoción... 101

Segundo, apropiarse de la lectura (en su doble condición de hecho natural y cultural, no restringido a lo lingüístico) y considerarla como función básica de intermediación entre las necesidades de información y su satisfacción. Pero sobre todo, como una actividad potencialmente emancipadora del hombre. ${ }^{6}$

Con estas herramientas, la biblioteca podrá comprometerse con tareas sociales muy concretas y actuales, entre las cuales están:

Apoyar la educación permanente y el reciclaje laboral. La relación entre biblioteca y educación no se restringe a la biblioteca escolar, universitaria o pública. En esta dimensión todas las bibliotecas comparten una función básica: la educación permanente como actividad que permite al hombre, entre otras cosas, adecuarse a los cambios sociales y laborales. D ice Ezequiel Ander Egg: "la E ducación permanente está centrada en la necesidad de una capacitación continua. [ligada a ella] aparece la necesidad de reciclaje: [...] los conocimientos quedan rápidamente envejecidos y necesitamos una formación continua." ${ }^{7}$

Combatir el consumismo y el uso alienante del tiempo libre. Consumo alienado como causa y efecto de la creciente futilidad de la vida, de los días que pasan bajo los afanes del producir y consumir bajo necesidades impuestas, conductas masivas y repetitivas, estéticas de lo grotesco, afanes de la evasión (lo virtual como nueva forma de escape).

Trabajar por aminorar el desarraigo cultural que se genera en las grandes ciudades. "El desarraigo se produce, precisamente, cuando la persona, como miembro de una familia o como ser social no se siente enraizado en un grupo o en una comunidad con la que pueda identificarse plenamente. Consecuentemente, la ciudad se hace algo ajeno al ciudadano y... cada ciudadano se convierte en algo ajeno a la ciudad." 8

D esde esa triple perspectiva, la funcionalidad social de la biblioteca reviste hondos compromisos, inquietantes retos que la llaman a reconsiderar su objeto y lugar dentro de las comunidades. Y frente a ello, tiene hoy que profundizar en la comprensión de lo que puede hacer, basándose en la tarea de informar e informarse (su función social básica), como lo que la hace vigente en las sociedades.

En todo esto se producen, quiérase o no, fenómenos de consumo, por lo que es lógico que la responsabilidad bibliotecaria no se cumpla atendiendo mecánicamente

6 Emancipación, en este contexto, alude a la acción de liberarse de las determinantes internas que afectando negativamente el nivel moral e ideológico, llevan a una vida alienada, no genuina. Esta alienación favorece el juego de otros con la existencia anímica y espiritual del individuo y las comunidades, lo que genera terribles injusticias en lo material. La emancipación se inicia con el convencimiento de la urgencia de ser, no solo de estar o de tener.

7 Ander Egg, Ezequiel. Metoddogáa y prádica de la animacón socioaltural / Ezequiel Ander Egg. Buenos Aires Humanitas, 1984.

8 Ander Egg, qp at 
las demandas de información. En esto términos, una biblioteca debería integrar también un esfuerzo permanente por favorecer el consumo no alienado ni alienante de información. He aquí la necesidad de promover usuarios que sean lectores activos y críticos, no sólo en sus áreas específicas de interés, sino también en el mundo y en su propia cultura.

\section{Cómo entender la promoción de la lectura en la biblioteca: posi- ción y sentido de la promoción de la lectura en la institución bibliotecaria}

No obstante la necesidad de impulsar la promoción de la lectura como acción estratégica de la biblioteca, no puede olvidarse que no se trata de ninguna cruzada redentora del hombre 0 de las comunidades. Se pretende únicamente difundir la lectura como un derecho, como un importante instrumento para la vida. Una práctica necesaria para integrarse a la vida colectiva en sociedades con supremacía de la lectoescritura (en las que es evidente su hegemonía sobre otras posibilidades de comunicación: la oralidad, por ejemplo). Espera la promoción de la lectura, eso sí, que la lectura se oriente siempre hacia la construcción de opciones, de espacios de encuentro, de fortalecimiento de la individualidad activa dentro de una también activa vida comunitaria. Porque es cierto que "algunas personas dedican parte de su tiempo libre a leer [pero...] habría que preguntarse qué leen [...] porque una actividad no es en sí misma una forma que ayuda al propio desarrollo. Algo tan inocente como los cómics o historietas [podríamos agregar las publicaciones pornográficas, los textos en INTERNET que enseñan la construcción de bombas, etc.] , son medios para influir ideológicamente a quienes se dedican a su lectura." 9

Innegablemente la promoción de la lectura acarrea efectos institucionales y sociales aún no apreciados a cabalidad. Efectos que pueden ser evidenciados, a manera de ejemplo, en los compromisos de acompañamiento que empiezan a serle demandados a la biblioteca por parte de los lectores (satisfacción de necesidades de lectura; integración de la biblioteca a proyectos comunitarios, como el trabajo con jóvenes, actividades de uso del tiempo libre, etcétera). Dicho de otra manera, a medida que el ciudadano toma conciencia de sus potencialidades y dinámicas como lector, se acerca a la biblioteca, porque empieza a reconocer el lugar que ésta ocupa dentro de su proyecto de vida.

Y es claro que si la biblioteca quiere responder adecuadamente a ello debe ahondar en la comprensión de su misiónsoial einstituional, y plantearse un papel emancipador, por medio del cual colabore en los procesos de constitución de una mejor vida 
Propuesta para el desarmollo de un programa de formación en promoción... 103

individual y comunitaria. ${ }^{10} \mathrm{Y}$ cumpliendo ese papel, debe intentar movilizar y recrear las significaciones (por lo común reducidas, endiosadas o academizadas) que normalmente tienen las personas y las comunidades sobre la lectura.

\section{Propósitos de la promoción de la lectura en la biblioteca}

\section{Propósito general}

Relacionar a las personas y comunidades con la lectura como actividad vital, de tal forma que:

* Inicien la revalorización de su propia condición lectora (personal y colectiva)

* Comprendan la importancia que puede llegar a tener la lectura en los fines de emancipación, participación y construcción de opciones de vida.

\section{Propósitos específicos}

En relación con el hogar: biblioteca y educación incidental

* Propiciar, dentro del hogar, la construcción de actitudes y valoraciones positivas de la lectura. Esto es, que sea apreciada y vivida como una actividad cotidiana. Para ello la biblioteca debe comprometerse con el suministrodemateiales deleturaque satisfagan las necesidades de información del hogar (cocina, crianza, arreglos domésticos, trámites, etcétera), en un ambiente de permanenteinteracción entre bibliotecario y comunidad: sujetos que entrelazan sus funciones de informar e informarse dentro de espacios de transformación mutua.

En relación con la escuela: biblioteca y educación formal

* Promover una nueva relación del educador con la lectura, de forma que la conciba como una actividad cultural íntimamente integrada a la vida individual y colectiva.

* Apoyar la transformación de las prácticas pedagógicas de formación y promoción del lector utilizadas en el espacio escolar.

* Favorecer la apropiación de herramientas conceptuales y metodológicas para el diseño y puesta en marcha de programas de animación de la lectura dentro de los PEI (Proyectos Educativos Institucionales).

10 Es evidente como rodeando las prácticas de promoción de la lectura desde la biblioteca, se encuentra un conjunto importantísimo de posibilidades de trabajo social de la biblioteca. La promoción de la lectura debe siempre funcionar como invitación a que el hombre se vincule a los otros, a que construya junto con otros, no sólo en su tiempo de trabajo sino también en su tiempo libre. Como dice Puig Picart, "[...] el tiempo desocupado se va transformando en un tiempo ideal para el desarrollo comunitario. Es un tiempo para socializarnos. Para usar y hacer ciudad. En la asociación , en el club. En la ciudad que se extiende más allá de la privacidad egoísta..." De ahí el valor que tiene el proyecto bibliotecario público, y la propuesta de la biblioteca popular como lugar de encuentro, lugar de vinculación, lugar de comunicación. Puig Picart, Toni. Animacón socicultural. Cultura y temitorio Madrid : Popular, 1992. 
En cuanto a la Biblioteca consigo misma: la biblioteca como tercer espacio educativo

* Promover la cualificación de la labor sociocultural de la biblioteca convirtiéndola en un espacio de producción de nuevos sentidos y significaciones del mundo, del otro y de uno mismo.

* Animar el encuentro productivo entre el lector y los materiales de lectura:

\section{¿Cómo puede la biblioteca promover la lectura?}

Es claro que la promoción de la lectura debe ser introyectada por la biblioteca como una práctica permanente, algo que cruza toda su estructura. Promover la lectura en la biblioteca no es tarea de uno u otro personaje, sino una funcionalidad propia a todos los que integran el equipo de trabajo. No obstante para efectos prácticos es necesario decir que una biblioteca puede promover la lectura con base en dos estructuras.

\section{A través de la estructura regular de servicios}

Servicio de referencia. Acercamiento directo del lector a los materiales de lectura a través del estudio de sus necesidades y expectativas lectoras. La referencia es una acción de promoción de la lectura, en la medida en que construye los caminos por los cuales el lector llega efectivamente a los materiales de lectura. El referenista es el primer y permanente promotor y animador de la lectura en la biblioteca. Para ello debe comprender que la primera actividad de animación a la lectura que él encara, es la comunicación con el otro dirigida a reconocer sus necesidades de información. Basándose en éstas, podrá cumplir la más importante acción de promoción de la lectura: hacer significativos (por hacerlos cercanos al hombre) los materiales de lectura que se coleccionan en la biblioteca.

O tras actividades de promoción de la lectura posibles de realizar a partir del servicio de referencia, son:

- La diseminación selectiva de información (D SI)

- Los servicios de alerta

- Los ficheros de usuario - intereses lectores

- Las bolsas de contacto lector (servicio que pretende poner en contacto lectores con intereses lectores similares)

- La promoción de colecciones o materiales específicos dentro y fuera de la biblioteca (efemérides, temas de interés actual, etcétera).

- La elaboración y difusión de reseñas y listados de libros para grupos especiales (desempleados, amas de casas, jóvenes, etcétera).

* Servicio de préstamo domiciliar: Encuentro del lector con los materiales por fuera de la biblioteca, en espacios donde desarrolla su cotidianidad y puede ejercer la lectura. El préstamo domiciliar es una acción de promoción 
de la lectura y porque obvia las barreras existentes entre los lectores y los materiales de lectura y favorece con ello mayores usos de la lectura.

El suministro de materiales de lectura debe ser ágil, abundante, variado y libre de requisitos onerosos, a la vez que creativo y atrevido. Un listado de servicios alternativos de préstamo domiciliar (ofrecidos fuera del espacio bibliotecario) puede echar mano de:

- Cajas Viajeras

- Colecciones itinerantes de materiales de lectura, entregadas en comodato a amas de casa, que puedan recorrer algunos hogares pilotos (previamente establecidos como focos de difusión de los materiales de lectura), en los que pueden realizarse algunas actividades básicas de animación de la lectura: lectura en voz alta, lectura mental, narración, préstamo, etcétera.

- Pequeñas bibliotecas de esquina o zonas comunales. Como los Paraderos Para Libros Para Parques(PPP). ${ }^{11}$

- Colecciones de vacaciones (pequeña cantidad de materiales de lectura para ser usados durante el período de vacaciones escolares y laborales).

- Préstamo de materiales con entrega a domicilio (con o sin costo de transporte y embalaje).

- Préstamo de materiales durante periodos no convencionales (durante convalecencias, viajes laborales, etcétera.

Servicio de información a la comunidad (SIC). Recuperación, organización y difusión de información de y para la comunidad en un contexto de identidad cultural y universalización del pensamiento y de la vivencia ciudadana. El servicio de información a la comunidad será una acción de promoción de la lectura en la medida que logre vincular la lectura como herramienta imprescindible al acto de informarse e informar.

La biblioteca se enfrenta no sólo a satisfacer necesidades de información estructurada (aquella que se basó en los principios rectores de un arte, ciencia, tecnología, etcétera), sino ante todo, y siempre, a la satisfacción de las necesidades de información generadas en la vida cotidiana: salud, seguridad, participación, gobierno, etcétera. Ante esta doble perspectiva, la biblioteca puede desarrollar estrategias que intenten integrar una y otra necesidades. A esto se llama "hacer inteligente" a la sociedad por la vía de hacer significativo - dentro de las necesidades reales de desarrollo de las

11 Los Paraderos Para Libros Para Parques, son un servicio que FUnd ALECTURA (O rganización Privada) presta en Colombia en asociación con otras instituciones culturales. Están conformados por una estructura construida con metal resistente a la interperie y diseñados de tal modo que en su interior quepan 300 libros atractivos y de buena calidad. Se supone que deben ser capaces de satisfacer los intereses lectores de niños, jóvenes y adultos. En Medellín funcionan en asocio con COMFENALCO. 
comunidades y de los hombres- el cúmulo de conocimiento humano dispuesto en los materiales de lectura.

* Servicio de educación de usuarios: Conexión del lector con la estructura bibliotecaria. Pretende que éste conozca y valore críticamente los diferentes servicios que se le ofrecen, y también que desarrolle habilidades mínimas de uso y manejo de la información en sus diferentes soportes. El servicio de educación de usuarios es una acción de promoción de la lectura, en la medida en que motive y le muestre a los lectores las múltiples posibilidades lectoras, y la manera de llegar a los materiales de lectura.

Algunas actividades de promoción y animación de la lectura que pueden emprenderse a partir de esta área, son:

- El desarrollo de talleres para el manejo de fuentes de información propias a las áreas de interés de los usuarios (profesores, desempleados, etcétera). Fuentes regulares como los periódicos, directorios telefónicos; fuentes más especializadas como resúmenes, tablas, etcétera.

- La organización de clubes de usuarios con intereses similares

- La organización de grupos de amigos de la biblioteca

* A través de una estructura directa de promoción de la lectura: En el medio bibliotecario colombiano (diríase que en el campo de los servicios bibliotecarios públicos), la tendencia administrativa actual es conformar áreas especializadas responsables de la formulación y aplicación de estrategias de promoción de la lectura a partir de la biblioteca. A la vez se busca el desarrollo estructurado de acciones de animación de la lectura. Estas áreas tienen un valor superlativo dentro de los propósitos de supervivencia y validación social de las bibliotecas que los organizan. No obstante, debe tenerse muy en cuenta que, mal concebidos, tales servicios pueden llegar a focalizar el trabajo de promoción hacia sólo algunos de los bibliotecarios (llegando el otro personal a considerar, por apreciación incorrecta, que sólo los llamados "promtares deletura" están autorizados por título y experiencia a trabajar en la promoción del lector).

D e cualquier modo son tarea de las estructuras especiales de promoción de la lectura dentro de las bibliotecas:

* En general: orientar la biblioteca o sistema bibliotecario hacia el desarrollo de productos y servicios que apoyen siempre los propósitos de promoción social de la lectura; para ello deberá:

a. Coordinar la formulación de las políticas de promoción de la lectura de la institución

b. Coordinar el trabajo de integración de áreas al interior de la biblioteca 0 sistema tomando la promoción de la lectura como eje central del proceso.

c. Coordinar los contactos interinstitucionales generados en la promoción de la lectura 
d. Capacitar al personal bibliotecario en los propósitos y metodología de la promoción de la lectura, según sus funciones y tareas.

* En particular, elaborar, ejecutar y controlar planes, programas y proyectos de promoción y animación de la lectura, como campañas de lectura; campañas de promoción del libro; campañas de promoción de la biblioteca; eventos bibliotecarios sobre la lectura, el libro y la biblioteca (seminarios, foros, exposiciones, etcétera); debates sobre la biblioteca; programas de formación de maestros; padres de familia, bibliotecarios, etcétera, basados en los propósitos y metodologías de trabajo de la promoción de la lectura; publicidad bibliotecaria; ferias de la lectura; programa regular de "Hora del Cuento"; visitas de grupos de escuelas y colegios; exposiciones; programas de Cajas Viajeras; atención a empresas; programas de lectura en voz alta; de narración, etcétera.

\section{HACIA UNA PROPUESTA DE DESARROLLO \\ DEL CAMPO DE LA PROMOCIÓN DE LA LECTURA \\ EN LAS ESCUELAS DE IBLIOTECOLOGÍA}

Ante las problemáticas de mundo y las tendencias e iniciativas bibliotecarias arriba planteadas, es urgente considerar caminos para desarrollar el campo de la promoción de la lectura en la escuelas de bibliotecología. Las siguientes ideas sustentan el plan de trabajo que un docente del área debería poder desarrollar. Estas ideas se proponen a partir de un convencimiento básico: la escuela de bibliotecología debe convertirse hoy, en el contexto latinoamericano, en un espacio académico de formación de personal bibliotecario sensible, comprometido y capaz frente a las problemáticas de la lectura y el lector.

El programa no se concibe atado únicamente al currículum del pregrado. Muy al contrario, se integran también otros sujetos, espacios y regiones a los tradicionalmente atendidos por la actividad académica tradicional. Es claro que en virtud de sus amplios compromisos sociales, la universidad latinoamericana debe extenderse a sectores e instituciones sociales como los sectores bibliotecarios, el popular, el escolar, las casas de la cultura, etcétera.

\section{La problematización del campo de trabajo}

Cualquier propuesta del área tendría que partir de identificar la problemática general en la que pretende intervenir. Ésta puede ser enunciada en los siguientes puntos:

* Escasa conceptualización disciplinaria en la universidad latinoamericana sobre la promoción de la lectura. La bibliotecología latinoamericana, y particularmente la colombiana, no logra integrar decididamente a la lectura entre sus 
responsabilidades epistemológicas y sociales en general. Pero la idea de una unidad de información como agencia de transferencia de información que no se pregunta por las cualidades y calidades de las competencias y habilidades de lectura y escritura de sus usuarios, es totalmente absurda.

* Dificultad en el medio para objetivar y hacer transmisibles las prácticas propias de la promoción de la lectura.

* Dificultad para entender e integrar la promoción de la lectura como un asunto fundamental en los procesos de gestión cultural emprendidos por las unidades de información, otras instituciones sociales y la combinación entre ellas.

* Focalización inequitativa de las prácticas de promoción de la lectura hacia las bibliotecas infantiles, escolares y públicas preferentemente, en desmedro de las otras unidades de información.

* Baja incidencia de las escuelas de bibliotecología en el desarrollo de la promoción de la lectura como campo de trabajo sociocultural.

* Carencias y dificultades del personal bibliotecario en el ejercicio de su condición lectora.

* D esconocimiento de la normatividad bibliotecaria relacionada con la esfera de influencia social de la promoción de la lectura.

* Posibilidades reducidas de formación intensiva y continuada del personal bibliotecario como promotores efectivos de la lectura.

\section{Estrategias que deberían ser desarrolladas en el área de promoción de la lectura en un programa de formación niversitaria}

La estrategias están vinculadas a las tres funciones básicas universitarias: docencia, investigación y extensión.

* Investigación teórica de base en el área: por ejemplo, estado del arte, legislación que ampare el desarrollo de prácticas en el campo.

* Investigación de campo en el área. Por ejemplo, investigación sobre las prácticas específicas de animación de la lectura en las bibliotecas públicas.

* Fortalecimiento los procesos de escritura con el objetivo de ir creando un compusbibliotecológico en el campo de la promoción de la lectura

* D esarrollo de asignaturas específicas sobre las relaciones entre biblioteca y lectura, y teoría de la Lectura.

* Desarrollo de eventos de educación continuada dirigida a egresados.

* Desarrollo de eventos educativos en el área para personal bibliotecario y otros sujetos participantes en la formación y promoción de los lectores, ahí donde dentro de los planes de desarrollo de las escuelas se haga necesario.

* O rganización y realización de eventos académicos en el área, en asociación con otras instituciones que trabajen en el campo. 


\section{Principales núcleos temáticos orientadores del programa}

\begin{tabular}{|c|c|c|c|}
\hline $\begin{array}{c}1 . \\
\text { Concepto } \\
\text { y conceptualización } \\
\text { de la P.L. }\end{array}$ & $\begin{array}{c}2 . \\
\text { Las unidades de } \\
\text { información y la } \\
\text { promoción de la } \\
\quad \text { lectura }\end{array}$ & $\begin{array}{c}3 . \\
\text { El promotor de la } \\
\text { lectura (énfasis en el } \\
\text { bibliotecólogo) y la } \\
\text { promoción de la } \\
\text { lectura }\end{array}$ & $\begin{array}{c}4 . \\
\text { Gestión de la } \\
\text { promoción de la } \\
\text { lectura en las } \\
\text { unidades de } \\
\text { información }\end{array}$ \\
\hline $\begin{array}{l}\text { 1. Contexto social } \\
\text { dentro del cual se ins- } \\
\text { cribe la formación de } \\
\text { lectores. } \\
\text { 2. Conceptualización } \\
\text { básica: } \\
\text { - Literagy (Leer, Es- } \\
\text { cribir) } \\
\text { - Promoción de la } \\
\text { lectura } \\
\text { - Animación a la lec- } \\
\text { tura } \\
\text { 3. La promoción de la } \\
\text { lectura como práctica } \\
\text { de carácter socio-cul- } \\
\text { tural. } \\
\text { 4. Las instituciones } \\
\text { promotoras de la lec- } \\
\text { tura: problemática, } \\
\text { interrelaciones y pers- } \\
\text { pectivas de integra- } \\
\text { ción. }\end{array}$ & $\begin{array}{l}\text { 1. A siento epistemo- } \\
\text { lógico de la bibliote- } \\
\text { cología y necesidad de } \\
\text { lapromoción delalec- } \\
\text { tura. } \\
\text { 2. Compromisos delas } \\
\text { unidades de informa- } \\
\text { ción con la promoción } \\
\text { de la lectura. } \\
\text { 3. Marco legal para el } \\
\text { ejercicio de la promo- } \\
\text { ción de la lectura con } \\
\text { base en las unidades de } \\
\text { información. } \\
4 . \text { El trabajo interins- } \\
\text { titucional e interdisci- } \\
\text { plinario de la promo- } \\
\text { ción de la lectura en la } \\
\text { unidades de informa- } \\
\text { ción. } \\
5 . \text { D isposición de la } \\
\text { unidad de informa- } \\
\text { ción para la promo- } \\
\text { ción de la lectura: } \\
5.1 \text { La arquitectura } \\
\text { regular del servicio. } \\
5.2 \text { E structuras bi- } \\
\text { bliotecológicas espe- } \\
\text { ciales para la promo- } \\
\text { ción de la lectura. }\end{array}$ & $\begin{array}{l}\text { 1. El status lector y su } \\
\text { relación con la calidad } \\
\text { de promotor de la lec- } \\
\text { tura } \\
2 . \text { El personal biblio- } \\
\text { tecario como promo- } \\
\text { tor de la lectura. }\end{array}$ & $\begin{array}{l}\text { 1. Naturaleza y moda- } \\
\text { lidades de las acciones } \\
\text { de promoción de lec- } \\
\text { tura impulsadas desde } \\
\text { las unidades de infor- } \\
\text { mación. } \\
\text { 2. Proyectos destaca- } \\
\text { bles al nivel local, re- } \\
\text { gional, latinoamerica- } \\
\text { no y mundial en el } \\
\text { campo de la promo- } \\
\text { ción de la lectura. } \\
\text { 3. Las actividades re- } \\
\text { gulares de promoción } \\
\text { dela lectura en las uni- } \\
\text { dades de información. } \\
\text { 4. Grencia de progra- } \\
\text { mas y proyectos bi- } \\
\text { bliotecológicos de } \\
\text { promoción de la lec- } \\
\text { tura. }\end{array}$ \\
\hline
\end{tabular}

5.

La animación a la lectura

Las estrategias de animación a la lectura. 


\section{Propósitos del programa}

Con relación a los sujetos en formación: estudiantes del pregrado, asistentes a eventos de educación continuada, bibliotecarios, etcétera.

* Propiciar transformaciones en la manera en que los sujetos que se forman o se despeñan en el campo bibliotecológico, conciben y viven su propia condición lectora y, en consecuencia, en la manera en que relacionan su trabajo bibliotecario con la formación y promoción de lectores autónomos y críticos.

* Aportar a los sujetos en formación herramientas conceptuales y prácticas para que puedan iniciar o mejorar procesos de promoción de la lectura.

Con relación a la bibliotecología como disciplina:

* Fomentar la reflexión disciplinaria e interdisciplinaria con respecto a la promoción de la lectura como campo de trabajo sociocultural.

* Aportar elementos a la construcción del discurso social de la bibliotecología, en tanto que se asuma la promoción de la lectura como área prioritaria de trabajo de la institución bibliotecaria.

Con relación a las escuelas de bibliotecología:

* Contribuir al desarrollo de la línea de investigación que la escuelas se hayan propuesto o estén proponiéndose en el campo de promoción de la lectura.

* Impulsar el buen posicionamiento de las escuelas dentro del ámbito de la investigación que sobre la lectura se ha venido desarrollando en América Latina.

\section{Generalidad de la propuesta pedagógica}

\section{El problema de los contenidos temáticos}

La temática debe estar, lógicamente, en continua actualización y renovación, y moverse siempre en una doble espiral de generalización y profundización. En tanto que se concibe al campo como de gran complejidad, se debe optar por la permanente contextualización y el encuadramiento temáticos. Por esta vía se abrirán nichos temáticos permanentes que relacionen a la bibliotecología con las otras áreas de investigación social (visión de la lectura y su promoción como campo inter y multidisciplinario). Por otro lado, se intensificará la investigación específica sobre nichos temáticos muy propios de la realización bibliotecológica en la promoción de la lectura como el diseño de servicios y la formación de lectores, el perfil del bibliotecario, etcétera (visión bibliotecológica de la lectura y su promoción).

Todas las actividades realizadas estarán atravesadas por una permanente reflexión pedagógica; es decir, estarán determinadas por las preguntas sobre la educabilidad en la bibliotecología y la enseñabilidad de las temáticas, habilidades y destrezas para el área de promoción de la lectura. 


\section{Las condiciones de los sujetos en formación}

En particular, estas condicionesse deberían inscribir a los ejes curriculares propios de cada escuela de bibliotecología para que pudieran promoverse en los estudiantes de la actitud investigativa, el conocimiento real de los sujetos y los espacios en los que se desenvuelve su vida cotidiana, así como el desarrollo de competencias y habilidades para el desempeño frente a problemas reales de formación y promoción de lectores. En este sentido, el programa deberá tener en cuenta:

* Las experiencias previas de los sujetos involucrados en los procesos de formación.

* La vinculación de personas expertas a los procesos de desarrollo del área.

* El contexto institucional, estatal y social en general dentro del cual se mueven las iniciativas de formación y la promoción de lectores.

\section{ACTIVIDAD INSTITUCIONAL SUGERIDA PARA INICIAR LA CONFORMACIÓN DE UN ÁREA DE FORMACIÓN EN PROMOCIÓN DE LA LECTURA}

Realice un taller de reflexión, o la actividad que le sea más propicia de acuerdo con sus condiciones institucionales, a partir del siguiente cuestionario. Agregue las preguntas que considere necesarias: ${ }^{12}$

\section{Radiografía básica del lugar que ocupa la promoción de la lectura en los intereses institucionales y académicos}

* Considere y registre por escrito:

1. Razones que motivan a la institución a emprender acciones de formación en el campo de la promoción de la lectura.

2. Razones para mantener el programa de formación en promoción de la lectura en el plan de estudios (si lo tiene integrado).

3. Razones por los cuales se necesita un cambio en las acciones de formación en promoción de la lectura.

4. Razones con las cuales defendería usted la formación en promoción de la lectura. en un tiempo difícil y austero.

Ubique los siguientes factores críticos necesarios para el óptimo funcionamiento de un programa de formación en promoción de la lectura en su institución educativa. Escríbalos.

12 Esta propuesta se diseñó a partir de una idea expuesta por Toni Puig Picart en su obra ya citada: Animadón socioaltural. Cultura y tenitorio 
1. Ideas fundamentales que deben sustentar la promoción de la lectura en su institución educativa.

2. Aspectos centrales que la formación en promoción de la lectura debe apoyar en la institución (referentes al desarrollo disciplinario, desarrollo institucional, desarrollo social y cultural, etcétera).

3. Tres necesidades/ problemas macrocurriculares (relación programa académico - hombre - sociedad) que sea necesario afrontar con el programa de formación en promoción de la lectura.

4. Políticas institucionales básicas de coordinación del programa de formación en promoción de la lectura.

5. Condiciones que debe reunir el personal docente para poder trabajar en el campo de formación en promoción de la lectura (perfil docente: competencias, habilidades, experiencias, proyecciones, etcétera).

6. Competencias, habilidades y experiencias que deben desarrollarse en los estudiantes.

7. Productos académicos que se ofrecerán a la sociedad (actividades de extensión institucional, convenios interinstitucionales, etcétera).

8. Condiciones básicas para el diseño de esos productos (políticas institucionales y principios de trabajo interinstitucional, conexión con programas gubernamentales, etcétera).

9. Pautas mínimas de calidad de los productos ofrecidos a la sociedad.

10. Aspectos que determinan los costos de los productos.

11. Grupos usuarios que serán sujetos de la oferta de los productos.

12. Características más notables de esos grupos (delimitaciones biosicológicas, sociodemográficas, político-económicas, educativas, etcétera).

13. Estrategias para hacer que los productos de promoción de la lectura ofrecidos a la sociedad lleguen a quienes no están siendo usuarios de ello y pertenecen a los grupos establecidos como prioritarias.

14. Estrategias para que los usuarios de los programas sean vinculados al diseño, realización y evaluación de los productos.

15. Estrategias para que los programas de promoción de la lectura que realizala institución se diferencien delos realizados por otras instituciones (sello institucional).

16. Criterios para determinar la vinculación del programa de formación en promoción de la lectura con otros programas propios de la institución educativa (dimensión interinstitucional).

17. Aspectos centrales para asegurar un buen trabajo de equipo.

18. Estrategias para asegurar una buena comunicación del programa a la comunidad académica y la sociedad (propuestas y productos). 
Propuesta para el desarrollo de un programa de formación en promoción... 113

\section{BIBLIOGRAFÍA}

BRUnNER, José Joaquín. AméicaLatinaenlaEnmüjadadelaModemidad D ocumento de trabajo. FLACSO - ProgramaChile. Serie:Educación y Cultura, no. 22, Santiago, abril de 1992.

Puig Picart, Toni. Animadón Socioaltural. Cultura y territorio. Madrid : Popular, 1992.

PASQUALI, Antonio. Comprender la Commicadón Caracas : Monte Avila, 1970, 289 p.

PETRUCCI, Armando. Leerpor Ler: un panenirparalaletura Barcelona. Alianza, 1994, p. 123.

AND ER Egg, Ezequiel. MecobloǵayPrádica delaAnimacón Sccioultural. Buenos Aires : Humanitas, 1984.

O RTEg a y G asset, José. "Misión del Bibliotecario". Madrid : Reiistade Occidante, 1962.

SO LÉ, Carlota. ModemidadyMoaknización México : Universidad Autónoma Metropolitana, 1998, xxi, 305 p.

BECK, U., A. Giddens y S. Lash. Modkmizacónneflexiva pdítica, tradioóny etética en d ardensoial modama Madrid : A lianza Universidad, c1994, $265 \mathrm{p}$.

AGNES, Heller. "Los motivos culturales como vehículo de cambio". En:

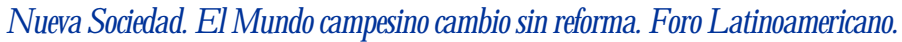
No 96(jul .-aga 1988), p. 39-49.

Álvarez, Didier, Luis Bernardo Yepes, Adriana Betancur. La promoción de la lectura. En: Yepes Osorio, Luis Bernardo. La promoción de la Letura: conceptos, materiales y autores Medellín : Comfenalco Antioquia, 1997, p. 11-22.

"La promoción de la lectura como trabajo bibliotecario de carácter sociocultural" . En: ReistaInterameicanadeBidlidtedoǵa Vol. 20, no. 1 (ene.jun. 1997), p. 7-24.

"La promoción de la lectura, una propuesta de acción para la escuela y la biblioteca". En: Hernández Carvajal, Juan Pablo. Animadón y promióndelaletura: considaracionesypropuestas Medellín : Comfenalco, 1997, p. 29-34.

TENZER, Nicolás. LaScieedadD æspditizada Barcelona. Paidós, 1992. 